\title{
Photoperiod and parturition period in isolated or paired rats : influence of sight deprivation and social conditions
}

\author{
E. Rodas ${ }^{1}$ and M.J. Bosc $2^{*}$ \\ 1 Instituto de Ciencias Fisiologicas, Facultad veterinaria, Alberto Lasplaces 1620, Montevideo, \\ Uruguay, and \\ 2 Station de physiologie de la reproduction, INRA, 37380 Nouzilly, France
}

(received 22 December 1988, accepted 6 March 1989)

\begin{abstract}
Summary - Time of delivery was studied in normal $(N)$ or enucleated $(E)$ rats. Isolated (1/cage) at mating (day 1 of gestation), they were all anaesthetized on day 8 and some of them were then blinded. After anaesthesia, they were kept either alone (N and E) or in homogeneous (NN and EE) and heterogeneous (NE) pairs either under a 12L-12D or a 2L-22D light-dark (LD) cycle. Activity, monitored throughout the rest of pregnancy in 2 homogeneous (NN and EE) and heterogeneous (NE) pairs of rats, kept a marked circadian rhythm under each light regimen. Birth distributions differed according to LD cycle in normal (N or NN) but not in enucleated ( $E$ and $E E$ ) rats. Under the $12 \mathrm{~L}-12 \mathrm{D}$ regimen, parturitions of $\mathrm{N}$ and $\mathrm{E}$ rats were divided into 2 parts, the majority occurred on the afternoon of day 22 before $21: 00 \mathrm{~h}$, the remainder were observed after $6: 00 \mathrm{~h}$ on day 23 . Under the $2 \mathrm{~L}-22 \mathrm{D}$ regimen, $\mathrm{N}$ rats gave birth over one period, mainly on day 23 , whereas $E$ rats had the same birth distribution as those subjected to the $12 \mathrm{~L}-12 \mathrm{D}$ LD cycle. In heterogeneous pairs of rats (NE), birth times were affected by photoperiod; under the $2 \mathrm{~L}-22 \mathrm{D}$ regimen it was intermediate between those of homogeneous pairs (NN and EE). These results indicate that the eyes were the first link of the nervous chain by which photoperiod influenced birth time. Social conditions may also modulate the photodependent mechanism in ways which remain to be determined.
\end{abstract}

rat - parturition - photoperiod - eyes — physical activity - social conditions

Résumé - Photopériode et moment de la parturition chez la rate élevée seule ou par deux. Influences de la privation de la vue et des conditions sociales. Le moment de la parturition a été étudié chez des rates normales $(N)$ ou énucléées (E). Isolées après la saillie (jour 1 de la gestation ou J1), elles ont été anesthésiées à J8 et certaines d'entre elles ont été alors énucléées. Après l'anesthésie, elles ont été gardées isolées ( $N$ ou E) ou en paires homogènes (NN et EE) et hétérogènes (NE) sous des régimes photopériodiques $12 L-12 D$ et $2 L-22 D$. De 19 à la fin de la gestation, l'activité générale, enregistrée chez deux paires homogènes et deux paires hétérogènes, a conservé un rythme circadien sous chaque régime photopériodique. Les distributions des naissances ont été différentes selon le régime "jour-nuit" chez les rates normales ( $N$ ou NN) mais non chez les énucléées ( $E$ ou $E E$ ). Sous le cycle $12 L-12 D$, les parturitions des rates normales et

\footnotetext{
* Author to whom correspondence should be addressed.
} 
énucléées se sont réparties en deux groupes; elles se sont produites en majorité au cours de l'après-midi du $22^{\circ}$ jour de la gestation avant 21:00 h, les autres ont été observées après 6:00 h le $23 e$ jour. Sous le cycle $2 L-22 D$, les rates normales ont mis bas sur une seule période principalement à $\mathrm{J} 23$ alors que les rates énucléées ont présenté une distribution des naissances équivalente à celle des rates soumises au cycle 12L-12D. Chez les paires hétérogènes (NE), les moments des naissances ont été affectés par le régime photopériodique. Sous le cycle $2 L-22 D$, leur distribution a été intermédiaire entre celles des paires homogènes (NN et EE). Ces résultats indiquent que les yeux sont le premier maillon de la chaîne nenveuse par laquelle la photopériode influence le moment de la naissance. IIs montrent aussi que les conditions sociales peuvent affecter ce mécanisme par d'autres voies qui restent à déterminer.

rat - moment de la naissance - photopériode — vue - conditions sociales

\section{Introduction}

In rats, photoperiod modulates the time of birth (Mitchell and Yochim, 1970; Plaut et al., 1970; Lincoln and Porter, 1976; Bosc and Nicolle, 1980a), and therefore the birth mechanism, by endogenous events which are finally integrated at the uterine and cervical levels. Other environmental cues can also modity the time of birth in this species, as in the case of periodic food presentation (Bosc and Nicolle, 1985; Bosc et al., 1986) and probably of social environment (Bosc and Nicolle, 1985). In order to evaluate the possibility of a social influence on the time of parturition, pairs of normal and/or blinded rats were subjected to two different light regimens. The two types of animals retained for this study also offered an opportunity to determine if the eyes were the first link in the neural pathway which mediates the effects of light on birth time.

\section{Materials and Methods}

\section{Animals}

Rats from strain 03 of our colony (Wistar origin) were kept in constant-temperature rooms $\left(20-21^{\circ} \mathrm{C}\right)$ under a standard light regimen of $14 \mathrm{~h}$ of light and $10 \mathrm{~h}$ of darkness (14L-10D) with lights on from 06:00 to 20:00 h (local winter time). After the age of 3 months, females were caged with a male for a night (a mating session). Mating (day 1 of pregnancy) was assessed by the presence of spermatozoa in the vaginal smear. Mated females were isolated one per cage and allocated to one of the experimental groups. The number of rats used in each group ranged between 20 and 44 for a total number of 325. Food (commercial pellets, U.A.R., Paris) and water were available ad libitum and renewed 2 or 3 times a week. The litter and cage were changed twice during gestation, the former on day 8 and the latter about one week later. Several mating sessions were necessary to complete all groups except one which was constituted in one night.

\section{Experimental groups}

The protocol included the anatomical status, the number of rats per box and the photoperiod. The anatomical status referred to two types of animals, normal (N) and enucleated $(E)$. All rats were anaesthetized on day 8 of gestation with diethyl oxide; they were weighed and the eyeballs of the enucleated rats were removed. Just after anaesthesia and/or after surgery, the rats were caged alone or in pairs to constitute the following groups: $\mathrm{N}$ (one normal), $\mathrm{E}$ (one enucleated), NN (two normals), EE (two enucleated) and NE (one normal + one enucleated). Under a $12 \mathrm{~L}-12 \mathrm{D}$ regimen (lights on from 06:00 to 18:00 h) a total of 102 parturitions were observed in these groups which were called: $\mathrm{N}_{12}(n=19), \mathrm{E}_{12}$ $(n=18), \mathrm{NN}_{12}(n=21), \mathrm{EE}_{12}(n=25)$ and $\mathrm{NE}_{12}(n=19)$. Under a $2 \mathrm{~L}-22 \mathrm{D}$ regimen (lights on from 06:00 to 08:00 h), 91 parturitions were recorded and the groups were then named: $\mathrm{N}_{2}(n=20), \mathrm{E}_{2}(n=20), \mathrm{NN}_{2}(n=19)$, $\mathrm{EE}_{2}(n=14)$ and $\mathrm{NE}_{2}(n=18)$. The two light 
regimens (12L-12D and $2 \mathrm{~L}-22 \mathrm{D})$ were started on day 9 of gestation and continued up until the end of the last parturition. At each mating session, several groups were put together in a room with a special light regimen. An additional group of normal rats (one per cage) was constituted after one mating session and subjected to continuous dim light (group $\mathrm{LL}, n=19$ ) from day 9 of gestation. This regimen was achieved as previously reported (Bosc, 1987), by placing an opaque shade around the light source in such a way as to indirectly illuminate the animals; at their levels, 0.6-1.4 lux were obtained (Luxmètre CL2010; Chauvin \& Arnoux, Paris).

\section{Observations and analyses}

The rats were inspected every hour from day $22-10: 00 \mathrm{~h}$, and the hour preceding the observations of the first young was considered as the time of birth. Litters with more than 2 young were retained for analysis and cumulated birth rates were then plotted and compared according to the non-parametric test of Kolmogorov-Smirnov (Siegel, 1956). An interval between birth and a given reference point (day 22-00:00 h) was also taken into account to compare the timings of parturition (variance analysis) (Vessereau, 1960).

The homogeneity of the groups was assessed on the basis of litter size, stillbirth rates and birth weight of live young (taken about half a day after parturition). Fertility was also compared among groups by taking into account all pregnant females (chi-square analysis) (Vessereau, 1960). Weights of the dams on day 8 of gestation and just after parturition were used as indicators of adaptation after surgery.

Activity was monitored from day 9 of gestation until parturition, as previously described (Bosc et al., 1986) in two pairs of rats in groups $\mathrm{NN}_{12}, \mathrm{NE}_{12}, \mathrm{EE}_{12}, \mathrm{NN}_{2}, \mathrm{NE}_{2}$ and $E E_{2}$. The main times of activity for each cage were visualized from day 10 of pregnancy until parturition. The hours during which the rats were active for at least $25 \%$ of the time were determined and represented by a dark horizontal bar for each $24 \mathrm{~h}$ period, each day being represented by a line underneath the bar. These records showed a pattern of activity resulting from the treatments. Subsequent analysis comprised the hourly times of activity over 12 consecutive days. The autocorrelations (Chatfield, 1978) were computed. In addition, periodogram analysis was performed with test periods varying between 12 and $30 \mathrm{~h}$ at $0.5-\mathrm{h}$ increments, according to the procedure of Enright (1965) adapted by Sokolove and Bushell (1978). All calculations were made on a Bull computer with appropriate programs (Becker and Chambers, 1984; David, 1984).

\section{Results}

The first parturitions were observed around noon of day 22 of gestation in all groups. Those following were spread over one or two periods, according to the group and to the light regimen.

When rats were kept alone, there were two periods of birth for groups $N_{12}$ and $E_{12}$ under the $12 L-12 D$ regimen and for group $E_{2}$ under the $2 L-22 D$ one. In the first period, births occurred mainly between 12:00 $\mathrm{h}$ and 21:00 $\mathrm{h}$ on day 22 . In groups $\mathrm{N}_{12}, \mathrm{E}_{12}$ and $\mathrm{E}_{2}(P>0.05)$, $63.1,52.9$ and $66.7 \%$ of the births were then respectively observed before 24:00 $\mathrm{h}$; the remaining ones occurred on day 23 during the second period starting at about $6: 00 \mathrm{~h}$, and the following 7 and $9 \mathrm{~h}$ without deliveries corresponded to the night for group $\mathrm{N}_{12}$ (Fig. 1). By contrast, group $\mathrm{N}_{2}$ rats under the $2 \mathrm{~L}-22 \mathrm{D}$ regimen gave birth over one period; $26.3 \%$ of deliveries were seen on day 22 and $73.7 \%$ on day 23 . This group differed from the preceding ones $(P<0.05)$.

When rats were grouped in pairs, births were also divided into two periods under the $12 \mathrm{~L}-12 \mathrm{D}$ regimen for groups $\mathrm{NN}_{12}$ and $\mathrm{NE}_{12}$. In these groups, 70.0 and $78.9 \%$ of births were observed on day 22 , a slightly higher percentage than in groups $\mathrm{N}_{12}$ and $\mathrm{E}_{12}(P>0.05)$ over the same times. The remaining ones occurred 7 and $9 \mathrm{~h}$ later after $6: 00 \mathrm{~h}$ on day 23. By comparison, births occurred in one period for groups $\mathrm{NN}_{2}$ and $\mathrm{NE}_{2}$ under the 


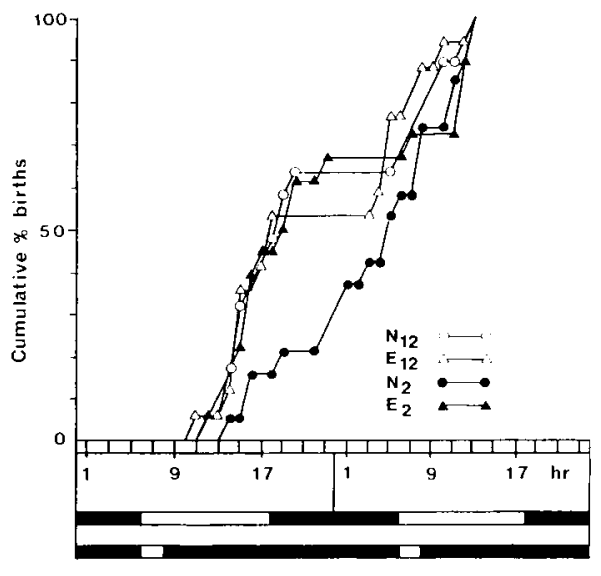

Day 22

Day 23

Fig. 1. Birth distribution on days 22 and 23 of gestation in normal (N) or blinded (E) rats caged alone under two light regimens. Groups $\mathrm{N}_{12}(\mathrm{O}-\mathrm{O} ; n=19)$ and $\mathrm{E}_{12}(\Delta-\Delta, n=17)$ were under a $12 \mathrm{~L}-12 \mathrm{D}$ regimen. Groups $\mathrm{N}_{2}$ $(-, n=19)$ and $\mathrm{E}_{2}(\boldsymbol{\Delta}-\boldsymbol{\Delta}, n=18)$ were under a $2 \mathrm{~L}-22 \mathrm{D}$ regimen. The two light regimens are indicated at the bottom. Group $\mathrm{N}_{2}$ is also represented in Fig. 2.

$2 L-22 D$ regimen; 44.4 and $55.6 \%$ were, respectively, observed before midnight on day 22 , the others occurring later. Fig. 2, showing these groups together with groups $\mathrm{N}_{2}$ and $E E_{2}$, illustrates the effects of anatomical status and of the number of rats per cage. When the interval between day 22-00:00 $\mathrm{h}$ and birth was taken into account, the mean times of parturition were, respectively : 27:46 $\mathrm{h}$ (SD $=$ 7:25 h), 24:36 h (SD = 7:59 h), 21:53 h $(\mathrm{SD}=7: 30 \mathrm{~h})$ and $21: 21 \mathrm{~h}(\mathrm{SD}=7: 23 \mathrm{~h})$ for groups $\mathrm{N}_{2}, \mathrm{NN}_{2}, \mathrm{NE}_{2}$ and $\mathrm{EE}_{2}(P<$ 0.05 for $\mathrm{N}_{2}$ vs $\mathrm{NE}_{2}$ and $\mathrm{EE}_{2}$ ).

If the difference due to the light regimen was obvious for normal rats kept alone or in homogeneous pairs (groups $\mathrm{N}_{12}$ and $\mathrm{NN}_{12}$ vs groups $\mathrm{N}_{2}$ and $\mathrm{NN}_{2}$ ), (Fig. 1), it was clear also for the heterogeneous pairs (groups $\mathrm{NE}_{12}$ and

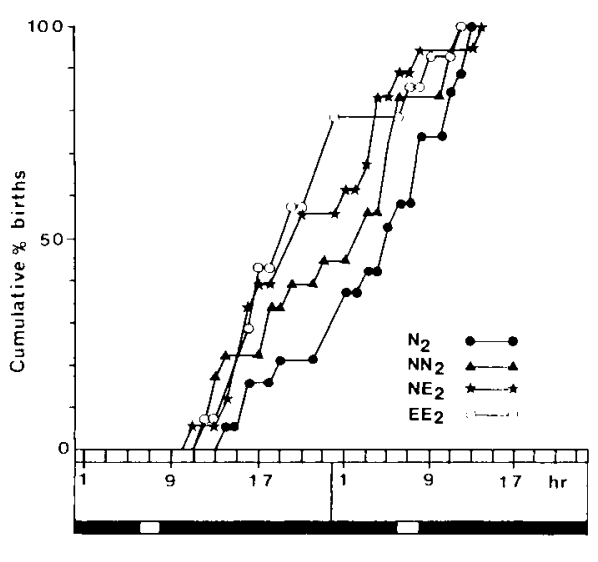

Day 22

Day 23

Fig. 2. Birth distribution on days 22 and 23 of gestation in normal $(N)$ or blinded $(E)$ rats caged alone or by twos under a 2L-22D regimen. Rats of groups $\mathrm{N}_{2}(-n=19)$ were caged alone; rats of groups $\mathrm{NN}_{2}(\boldsymbol{\Lambda}-\mathbf{A}$, $n=18), \mathrm{NE}_{2}$ (*-*, $n=18$ ) and $\mathrm{EE}_{2}(\mathrm{O}-\mathrm{O}$; $n=14$ ) by two. The light regimen is indicated at the bottom. Group $N_{2}$ is also represented in Fig. 1, group $\mathrm{NE}_{2}$ in Fig. 3 and group $\mathrm{EE}_{2}$ in Fig. 4.

$\mathrm{NE}_{2}$ ) (Fig. 3) (median test : $0.05<P<$ $0.1)$. However, in no group formed by these pairs, did birth times differ between the types of rat $(P>0.05)$. Finally, rats alone under continuous light (group LL) gave birth mainly on day $22(77.8 \%)$ as did rats of groups $E_{12}$ and $E_{2}$ (63.6 and $71.4 \%$, respectively; $P>0.05$ ) (Fig. 4 ).

Activity was concentrated within defined daily hours which were limited to the night in group $\mathrm{NN}_{12}$ (Fig. 5) or to the hours corresponding to the night of their preceding light regimen in group $\mathrm{NN}_{2}$ (Fig. 5). Blinded rats of groups $\mathrm{EE}_{12}$ (Fig. 5) or $\mathrm{EE}_{2}$ (Fig. 5) also evidenced main daily times of activity during the hours corresponding approximately to the night of their regimen preceding surgery. In pairs comprising normal and blinded rats, the same patterns were also observed 


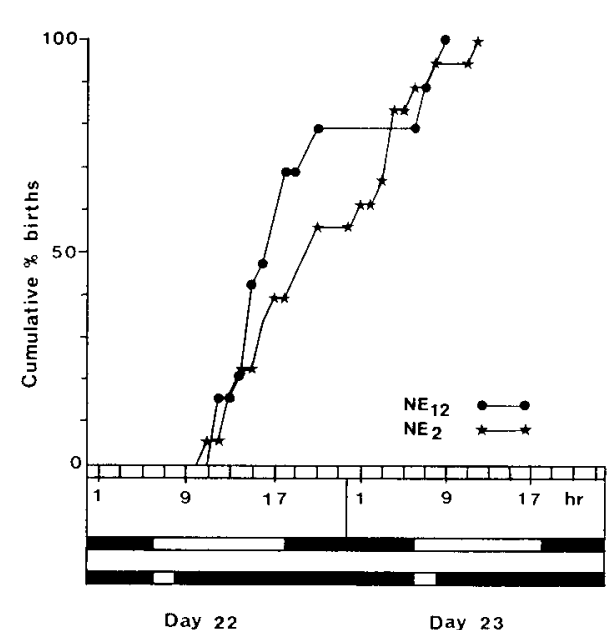

Fig. 3. Birth distribution on days 22 and 23 of gestation in pairs comprising normal and blinded rats under two light regimens. Rats of groups $\mathrm{NE}_{12}(-, n=19)$ were under a $12 \mathrm{~L}-12 \mathrm{D}$ regimen. Rats of group $\mathrm{NE}_{2}$ (*-* $n=18$ ) were under a $2 \mathrm{~L}-22 \mathrm{D}$ regimen. The two light regimens are seen at the bottom. Group $\mathrm{NE}_{2}$ is also represented in Fig. 2 .

(Fig. 5 for group $\mathrm{NE}_{12}$, Fig. 5 for group $\mathrm{NE}_{2}$ ); in a few cases, the daily activity was slightly shifted. The homogeneous pairs (groups $\mathrm{NN}_{12}, \mathrm{NN}_{2}, \mathrm{EE}_{12}$ and $\mathrm{EE}_{2}$ ) had autocorrelations which followed a clear sinusoidal pattern with an apparent period of $24 \mathrm{~h}$. This circadian periodicity was confirmed by the periodogram estimates (Fig. 6). The same period was also found in the heterogeneous pairs (groups $\mathrm{NE}_{12}$ and $\mathrm{NE}_{2}$ ) (Fig. 6) but the autocorrelations were less regular than in the other groups indicating some disturbances of circadian rhythm of activity.

All groups were homogeneous for their litter size $(9.9 \pm 2.5)$ and the number of live pups at birth $(9.6 \pm 2.4)$. There were however some variations, group $E_{12}$

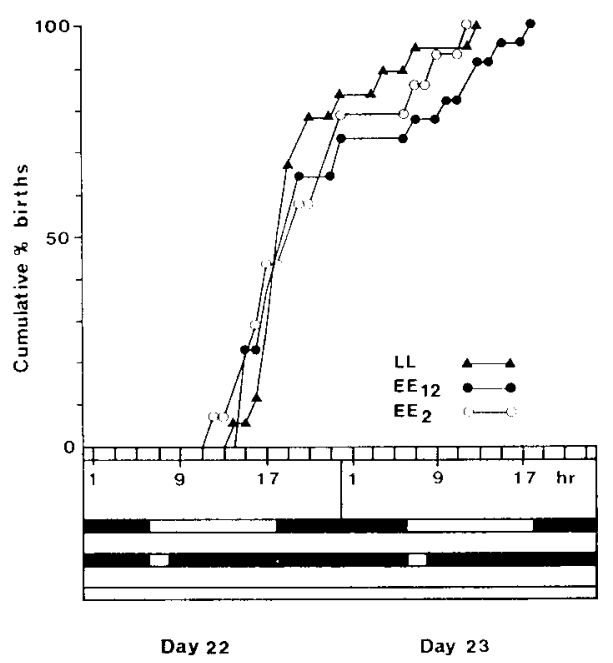

Fig. 4. Birth distribution on days 22 and 23 of gestation of normal rats caged alone or in pairs of enucleated (E) rats under different light regimens. Normal rats of group LL $(\boldsymbol{\Delta}-\boldsymbol{\Lambda}, n=$ 18) were under a dim constant light. Rats of groups $\mathrm{EE}_{12}(\longrightarrow, n=22)$ and $\mathrm{EE}_{2}(\mathrm{O}-\mathrm{O}$, $n=14$ ) were under a $12 \mathrm{~L}-12 \mathrm{D}$ and $\mathrm{a} 2 \mathrm{~L}-22 \mathrm{D}$ regimen, respectively. The light treatments are represented at the bottom. Group $\mathrm{EE}_{2}$ is also represented in Fig. 2.

having the smallest litter size $(8.6 \pm 3.3)$ and one of the largest stillborn rates $(8.9 \%)$. Stillbirth rates ranged between 2.6 and $13.7 \%$ and were not associated with particular treatments. Birth weights of live young did not differ among the groups ( $P$ $>0.05$ ). However, fertility was affected by anatomical status $(P<0.001)$, extirpation of the eyes leading to a significant reduction (54.7 vs $76.8 \%$ ). Fertility was particularly low in groups $\mathrm{E}_{2}(45.4 \%)$ and $\mathrm{EE}_{2}(43.7 \%)$. The dams were on the average a little heavier just after parturition than on day 8 of gestation in all groups, except in group $E_{2}$ in which they were a little lighter (on the average $7 \mathrm{~g}$ less). 

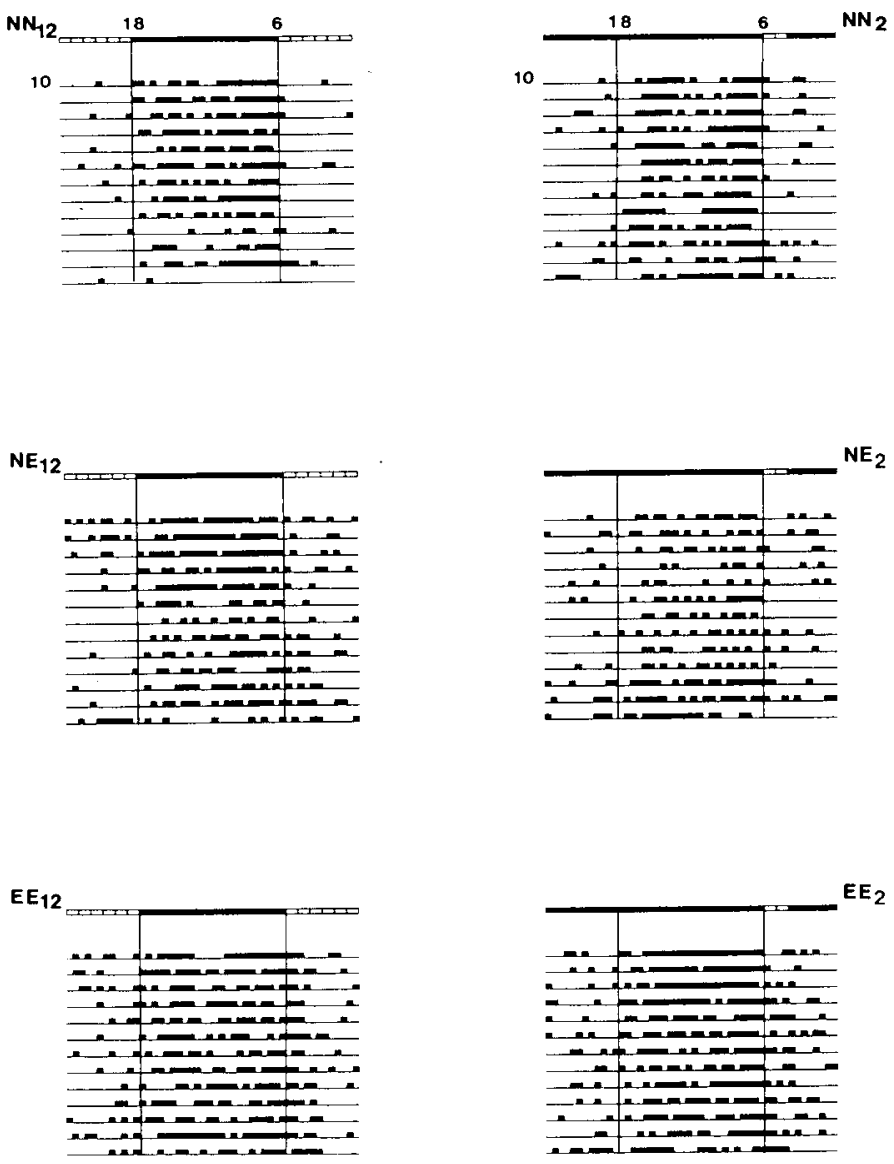

Fig. 5. Main daily periods of activity during the last 13 days of gestation in pairs of normal $(\mathrm{N})$ or enucleated $(E)$ rats. The light regimens $(12 L-12 D$ or $2 L-22 D)$ are given at the top of each panel (a pair of rats). Each line represents a 24-h period starting on day 10 of pregnancy at 12:00 h. Horizontal dark bars indicate an activity time of $>25 \%$ of the corresponding hour. Vertical lines indicate the dark phase of the $12 \mathrm{~L}-12 \mathrm{D}$ regimen.

\section{Discussion}

A comparison between groups of normal and blinded rats indicates that the eyes were the first link in the nervous pathway by which photoperiod influenced birth time in the rats. This agrees with the general assertion that light entrainment of circadian rhythms is mediated by the retina in mammals. Rodents do not have extra-retinal light perception (Moore, 1979; Rusak and Zucker, 1979), even if light is directly transmitted to the brain as shown in adult ewes (Van Brunt et al., $1964)$ or in rats and guinea pig fetuses (Jacques et al., 1987). 

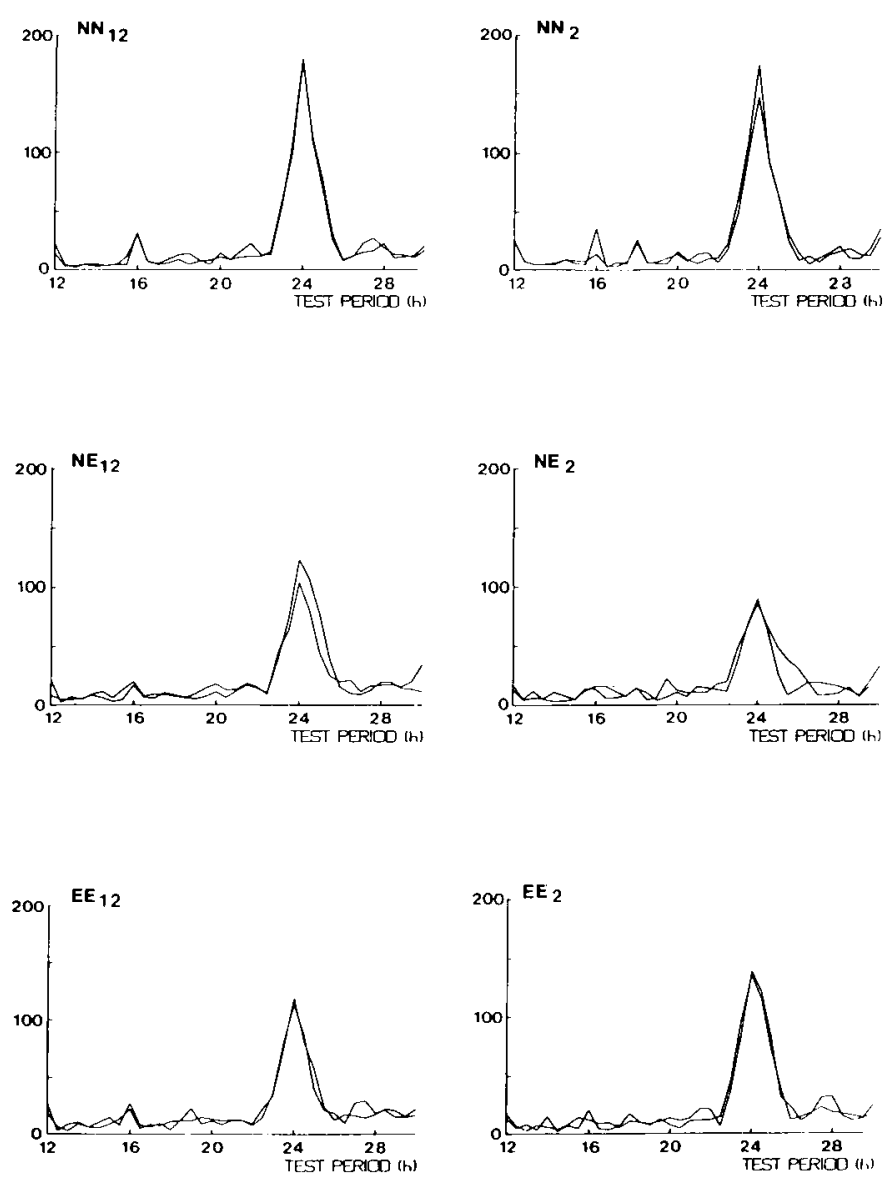

Fig. 6. Periodogram estimates of the hourly physical activity in pairs of normal $(N)$ or enucleated $(E)$ rats. Under each light regimen, two pairs of rats have been recorded. Groups $N_{12}, N_{12}$ and $E_{12}$ were under a $12 \mathrm{~L}-12 \mathrm{D}$ regimen. Groups $\mathrm{NN}_{2}, \mathrm{NE}_{2}$ and $\mathrm{EE}_{2}$ were under a $2 \mathrm{~L}-22 \mathrm{D}$ regimen.

This experiment also shows that social environment may influence the time of parturition in rats. The procedure of housing rats alone or by twos created social conditions which gave different birth distributions according to the anatomical status of the animals and the light regimen. Thus a pair comprising one normal and one enucleated rat gave a response intermediate between the homogeneous pairs of normal or enucleated animals under the $2 L-22 D$ regimen but not under the $12 \mathrm{~L}-12 \mathrm{D}$ (Figs. 2 and 3). This may be attributed to a reciprocal influence resulting from the effect of photoperiod on normal rats and from its lack of effect on the enucleated ones. This reciprocal influence therefore indicates the existence of a mechanism of substitution, the perception of light by the eyes being replaced by another stimulus which may act on the regulation of 
parturition. Birth is not the only reproductive event which may be affected by social control and this is not limited to the rat (McClintock, 1981). The problem now is to determine by which mechanism this environmental cue regulates birth time. In this respect, it would be interesting to know if this mechanism implicates the suprachiasmatic nuclei which mediate the effect of photoperiod on birth timing (Murakami et al., 1987; Reppert et al., 1987). It should be noted here that the social conditions were limited to the close environment of the animals but not to the general context, i.e., the room under the present conditions. Groups $\mathrm{N}_{2}, \mathrm{NN}_{2}, \mathrm{NE}_{2}$ and $\mathrm{EE}_{2}$ were in the same room (or light regimen) but had different birth distributions (Fig. 2).

This experiment also provides an insight into the endogenous organization of the photodependent mechanism. The pairs of normal rats had the same circadian periodicity of activity under the two light regimens (Figs. 5 and 6). The different distributions of births observed under these conditions (Fig. 1) illustrate therefore the specific effect of light given at a determined moment of the day. Light reduced to two morning hours delayed most of the parturitions to day 23 of gestation, just as a light flash given at the same times under a $8 \mathrm{~L}-16 \mathrm{D}$ regimen (Bosc and Nicolle, 1980b). These results confirm that the process of birth depends upon an endogenous rhythm of photosensitivity (Bosc and Nicolle, 1980b). The blinded rats which would free-run after surgery, presented the same circadian rhythm of activity (Figs. 5 and 6) as the normal rats. The apparent stability of this rhythm may be attributed to the short time interval between surgery and the end of gestation and/or perhaps because the rats were caged by twos. One may note also that blinded rats presented a break in delivery for several hours corresponding to the most active period of the day, as previously observed in other conditions (Bosc et al., 1986). This lack of birth for a significant time indicates that parturition can be initiated during given hours of the day according to a gate system which can be reset by photoperiod or other environmental cues (Bosc and Nicolle, 1985; Bosc et al., 1986).

Variations in litter size or stillbirth rate usually related to length of gestation or parturition cannot explain the differences observed among groups. Some problems of adaptation after surgery were nevertheless encountered in a group of enucleated rats (group $E_{2}$ ). Another effect observed in this experiment is the lower fertility of blinded rats. This decrease of fertility is perhaps due to the stress of surgery after the completion of implantation (Psychoyos, 1973), or it may result from unspecified effects of sight deprivation.

In conclusion, the integration of lighting conditions by the eyes is the way by which photoperiod modulates the time of birth in the rat. The use of normal and blinded animals shows that social environment may also play a role. It is interesting here to point out the flexibility of the neurohormonal mechanism by which birth time may be controlled by environmental cues.

\section{Acknowledgments}

This work was supported by the Institut National de la Recherche Agronomique. The authors thank Mrs. A. Nicolle and D. Ducelliez for their valuable help throughout the course of this experiment. They are grateful to MM. C. Cahier, P. Trezy and M. Vigneau for animal care. They also appreciate the assistance of Mr. D. Tanguy in carrying out the statistical analyses. 


\section{References}

Becker R.A. \& Chambers J.M. (1984) In : S An Interactive Environment for Data Analysis and Graphics. Wadsworth Advanced Book Program, Belmont, CA, p. 550

Bosc M.J. (1987) Time of parturition in rats after melatonin administration or change of photoperiod. J. Reprod. Fert. 80, 563-568

Bosc M.J. \& Nicolle A. (1980a) Influence of photoperiod on the time of parturition in the rat. 1. Effect of the length of daily illumination on normal or adrenalectomized animals. Reprod. Nutr. Dev. 20, 735-745

Bosc M.J. \& Nicolle A. (1980b) Influence of photoperiod on the time of parturition in the rat. II. Demonstration of a photoinducible phase and determination of some of its characteristics. Reprod. Nutr. Dev. 20, 939-948

Bosc M.J. \& Nicolle A. (1985) Influence of photoperiod on the time of birth in the rat. IV. Effects of an imposed feeding rhythm. Reprod. Nutr. Dev. 25, 39-48

Bosc M.J., Nicolle A. \& Ducelliez D. (1986) Time of birth and daily activity mediated by feeding rhythms in the pregnant rat. Reprod. Nutr. Dev. 26, 777-789

Chattield C. (1978) In : The Analysis of Time Series : Theory and Practice. Chapman and Hall, London, p. 263

David A. (1984) E.S.C. Etude des séries chronologiques (version 2). Université de Haute-Bretagne, Rennes, France, p. 41

Enright J.T. (1965) The search for rhythmicity in biological time series. J. Theoret. Biol. 8, 426468

Jacques S.L., Weaver D.R. \& Reppert S.M. (1987) Penetration of light into the uterus of pregnant mammals. Photochem. Photobiol. 45, 637-641

Lincoln D.W. \& Porter D.G. (1976) Timing of the photoperiod and the hour of birth in rats. Nature 260, 780-781
McClintock M.K. (1981) Social control of the ovarian cycle and the function of estrous synchrony. Am. Zool. 21, 243-256

Mitchell J.A. \& Yochim J.M. (1970) Influence of environmental lighting on duration of pregnancy in the rat. Endocrinology 87, 472-480

Moore R.Y. (1979) The anatomy of central neural mechanisms regulating endocrine rhythms. In : Endocrine Rhythms (Krieger D.T., ed.), Raven Press, New York, pp. 63-87

Murakami N., Abe T., Yokoyama M., Katsume A., Kuroda H. \& Etoh T. (1987) Effect of photoperiod, injection of pentobarbitone sodium or lesion of the suprachiasmatic nucleus on prepartum decrease of blood progesterone concentrations or time of birth in the rat. $J$. Reprod. Fert. 79, 325-333

Plaut S.M., Grota L.J., Ader R. \& Graham C.W. (1970) Effects of handling and the light dark cycle on the time of parturition in the rat. $L a b$. Anim. Care 20, 447-453

Psychoyos A. (1973) Endocrine control of egg implantation. In : Handbook of Physiology, Am. Physiol. Soc., pp. 187-215

Reppert S.M., Henshaw D., Schwartz W.J. \& Weaver D.R. (1987) The circadian-gated timing of birth in rats : disruption by maternal CNS lesions or by removal of the fetal brain. Brain Res. 403, 398-402

Rusak B. \& Zucker I. (1979) Neural regulation of circadian rhythms. Physiol. Rev. 59, 449-526 Siegel S. (1956) In : Non-parametric Statistics for the Behavioural Sciences. Int. Student, ed. McGraw-Hill, New York, p. 312

Sokolove P.G. \& Bushell W.N. (1978) The chisquare periodogram : its utility for analysis of circadian rhythms. J. Theoret. Biol. 72, 131-160

Van Brunt E.E., Shepherd M.D., Wall R.J., Gannong W.F. \& Clegg M.T. (1964) Penetration of light into the brain of mammals. Ann. N.Y. Acad. Sci. 117, 217-224

Vessereau A. (1960) In : Recherche et Expérimentation en Agriculture, Tome 2, Méthodes statistiques en Biologie et Agronomie. Baillières et Fils, Paris, p. 539 